Case Report

\title{
Plexiform schwannoma mimicking a salivary gland tumor: An unusual case report diagnosed in pediatric patient
}

\author{
Jean Nunes dos Santos ${ }^{\mathrm{a}, \mathrm{b}, *}$, Clarissa Araújo Silva Gurgel ${ }^{\mathrm{c}, \mathrm{d}}$, Eduardo Antônio Gonçalves Ramos ${ }^{\mathrm{d}}$, \\ Fernando Bastos Pereira Júnior ${ }^{\mathrm{e}}$, Iêda Margarida Crusoé-Rebello ${ }^{\mathrm{f}}$, Márcio Campos Oliveira ${ }^{\mathrm{c}}$ \\ ${ }^{a}$ Consultant in Oral Pathology at State University of Feira of Santana, Feira de Santana, Bahia, Brazil \\ ${ }^{\mathrm{b}}$ Department of Oral Pathology, Federal University of Bahia, Salvador, Bahia, Brazil \\ ' Department of Health/Oral Pathology of the State University of Feira of Santana, Feira de Santana, Bahia, Brazil \\ ${ }^{\mathrm{d}}$ Gonçalo Moniz Research Center - Oswaldo Cruz Foundation, Salvador, Bahia, Brazil \\ e Department of Health/Oral Surgery of the State University of Feira of Santana, Feira de Santana, Bahia, Brazil \\ ${ }^{\mathrm{f}}$ Department of Oral Radiology of Federal University of Bahia, Salvador, Bahia, Brazil
}

\section{A R T I C L E I N F O}

\section{Article history:}

Received 20 December 2010

Received in revised form 22 February 2011

Accepted 25 February 2011

Available online 1 April 2011

Keywords:

Plexiform schwannoma

Palate

Children

Salivary gland tumor

\begin{abstract}
A B S T R A C T
Plexiform schwannomas are extremely rare in the oral cavity. We report here the case of a 3-year-old child with plexiform schwannoma located in the hard palate. The tumor presented as a slowly growing nodule of about 6 months duration, mimicking clinically a salivary gland tumor. No signs of recurrence were observed after one year of follow-up. Benign peripheral nerve and salivary gland tumors should be included in the differential diagnosis of nodular lesions occurring in children.
\end{abstract}

(c) 2011 Elsevier Ireland Ltd. All rights reserved.

\section{Introduction}

Plexiform schwannoma is a rare benign peripheral nerve sheath tumor described for the first time by Harkin et al. [1], which macroscopically grows in a multinodular or plexiform pattern [2]. Plexiform schwannomas mainly affect young adults and children [1]. These tumors occur as solitary painless nodules in the region of the trunk, head and neck or upper limbs [3], and most are known to involve the skin and subcutaneous tissues [4,5].

Plexiform schwannomas are usually not associated with neurofibromatosis, but an association with neurofibromatosis type 2 has been described in some cases [6,7]. Histologically, these tumors are characterized by a biphasic pattern of Antoni A cellular areas and Antoni B hypocellular areas and the formation of Verocay bodies, a pattern similar to that observed in classical schwannomas [2].

Plexiform schwannomas are extremely rare in the oral cavity. To our knowledge, little is reported about oral plexiform schwannoma in the English-language literature. Therefore, we

\footnotetext{
* Corresponding author at: Av. Araújo Pinho, 62, Canela, Salvador, Bahia, Brazil 40110150. Tel.: +55 713283 9019; fax: +55 7132838962 .

E-mail address: jeanunes@ufba.br (J.N.d. Santos).
}

report here a case of oral plexiform schwannoma in a pediatric patient that mimicked a salivary gland tumor.

\section{Case report}

A 3-year-old black girl was seen at the Oral Lesion Referral Center of State University of Feira de Santana with a "lump in the roof of the mouth that was not improving" according to the report of the responsible person. Intraoral physical examination revealed an exophytic nodular lesion in the hard palate, which was firm on palpation and covered with normal-appearing mucosa. The lesion had slowly grown for 6-month duration and measured $1.6 \mathrm{~cm}$ in its major diameter. An association with trauma was ruled out. Extraoral physical examination revealed no noteworthy alterations. Thus, panoramic radiography and computed tomography were requested. The computed tomography scan showed a delimited and isodense lesion in the hard palate, which was apparently not encapsulated. There was no evidence of bone erosion. Based on the clinical hypothesis of pleomorphic adenoma, the lesion was surgically removed under general anesthesia using orotracheal intubation. The material was sent for histopathological analysis at the Laboratory of Pathological Anatomy, Department of Health/Oral Pathology, State University of Feira de Santana. Immunohistochemistry ruled out the possibility of a salivary gland tumor and the diagnosis of plexiform schwannoma was 

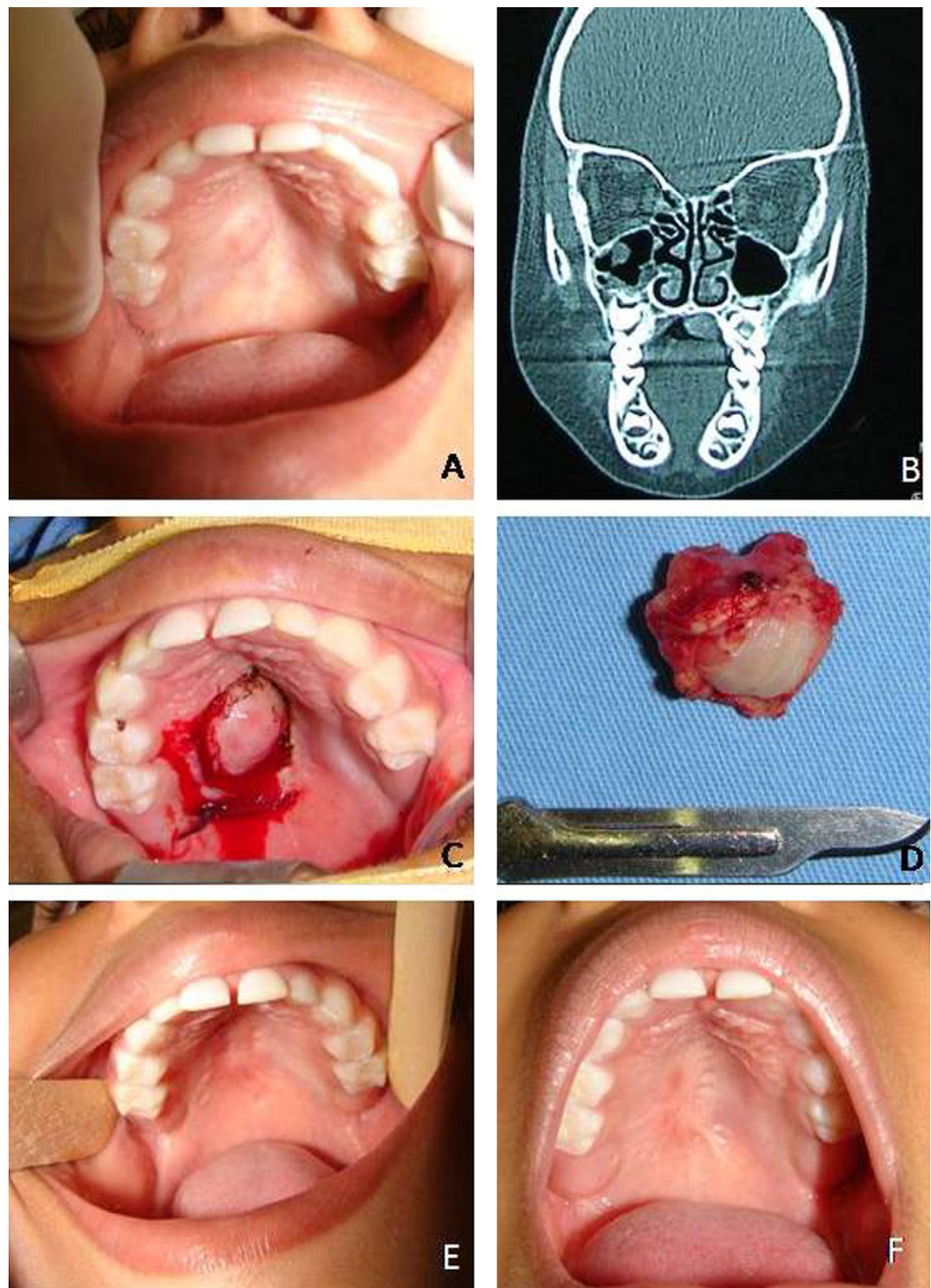

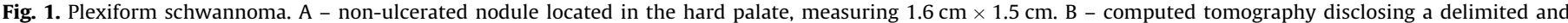

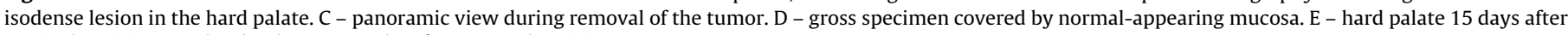
surgical excision. $\mathrm{F}$ - hard palate 6 months after surgical excision.

established. Although we were not capable of performing molecular testing, the possibility that the patient or her relatives had neurofibromatosis type 2 was investigated, but no signs or symptoms characterizing the syndrome were found. The patient showed no signs of recurrence one year after follow-up (Fig. 1A-F).

\section{Pathologic findings}

Grossly, the tumor had a brown color, oval shape, firm consistency and regular surface; it measured $1.6 \mathrm{~cm} \times 1.5 \mathrm{~cm} \times 1.3 \mathrm{~cm}$.

Microscopic examination showed multiple nodules surrounded by a fibrous capsule containing residual perineurium. The nodules mainly consisted of Antoni A tissue with aligned and compact spindle-shaped cells, which were often arranged in a nuclear palisade, and well-developed Verocay bodies. A fascicular or whorl pattern was occasionally observed. Areas of Antoni B tissue were less frequently seen. There were no signs of pleomorphism, mitoses, hemorrhage or necrosis, but the tumor showed nondestructive entrapment of well-differentiated salivary gland tissue (Fig. 2A-E).

Immunohistochemistry showed the presence of tumor cells that were strongly and diffusely positive for protein S-100 and vimentin in hyper- and hypocellular areas. Immunoreactivity to EMA was detected in perineurium and, eventually, in Antoni A 

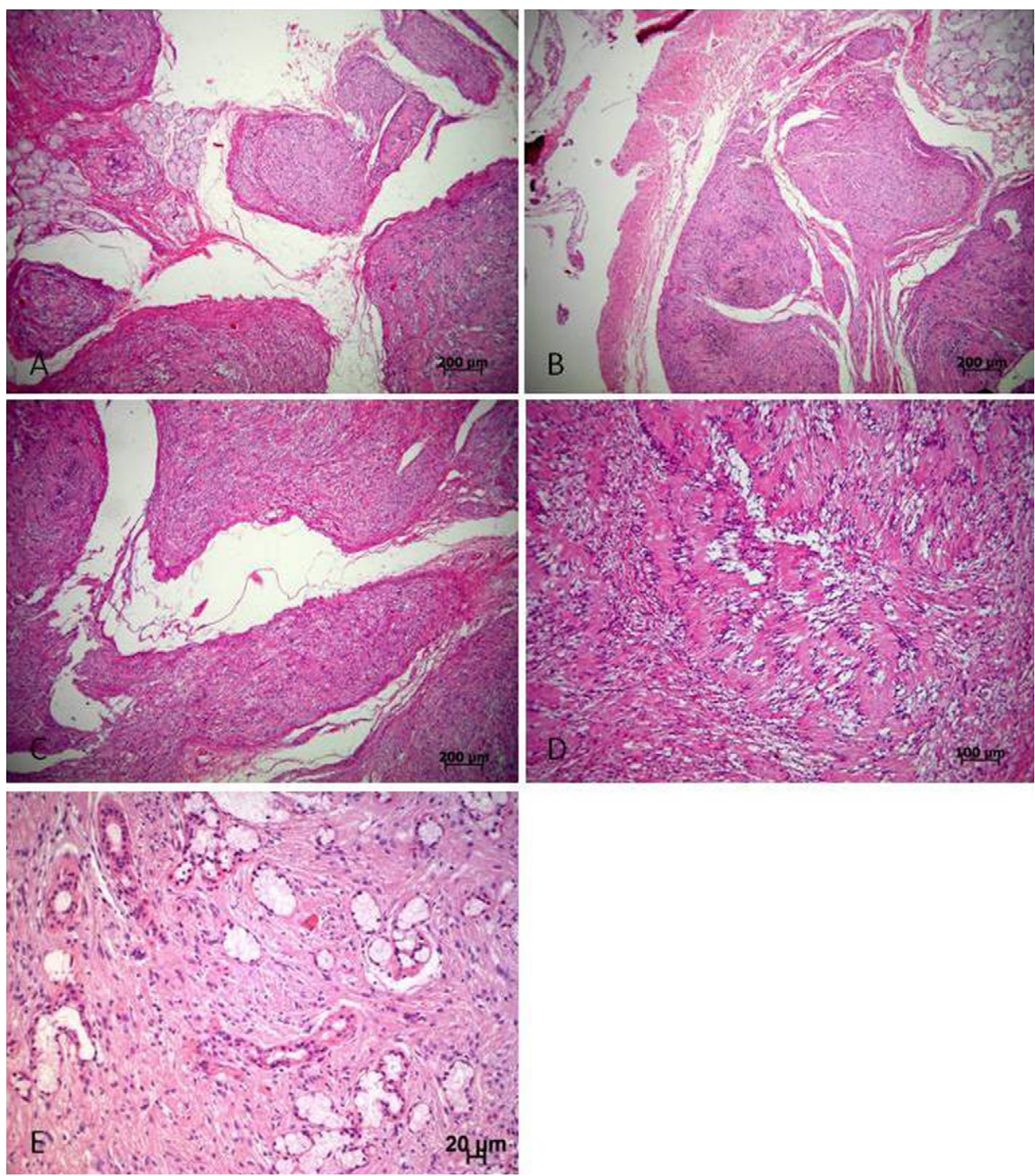

Fig. 2. Plexiform schwannoma. A and B - multiple well-delimited nodules close to normal salivary gland. C - nodules surrounded by a fibrous capsule. D - Antoni A tissue with aligned and compact spindle-shaped cells arranged in a nuclear palisade, and well-developed Verocay bodies as well as small vacuoles. E - Acini and glandular ducts amidst neoplasm.

areas. The perineurium was immunopositive for GFAP, but GFAPpositive spindle-shaped cells were also observed in some areas. CD57 immunoreactivity was occasionally detected in Antoni B areas and less frequently in spindle-shaped cells. Similarly, CD56 immunopositivity was observed in the region of the perineurium, as well as in Antoni A and Antoni B areas. Immunostaining for neurofilament, AE1/AE3 and calponin was negative and Ki-67immunopositive cells were rarely observed (Fig. 3A-E).

\section{Discussion}

Schwannomas rarely involve the oral cavity [8], accounting for $5 \%$ of all benign peripheral nerve tumors [3]. However, a small number of these tumors are identified as plexiform schwannomas according to their phenotypic aspects [9]. The latter are extremely rare in the oral cavity [8] especially in younger children under 5-years-old. To the best of our

Table 1

Reports of cases of plexiform schwannoma of the oral cavity published in the English-language literature.

\begin{tabular}{|c|c|c|c|c|c|c|c|c|c|}
\hline Reference & Country & Age (years) & Gender & Location & Size $(\mathrm{cm})$ & Duration & Treatment & Recurrence & $\begin{array}{l}\text { Association with syndrome } \\
\text { [neurofibromatosis?] }\end{array}$ \\
\hline Lobo et al [5] & Portugal & 7 & $\mathrm{~F}$ & Lower lip & 0.7 & 6 months & Excision & No & No \\
\hline Giovanni et al. [8] & Italy & 16 & M & Jugal mucosa & 3.0 & 10 years & Excision & Yes & No \\
\hline Krolls et al. [19] & USA & 21 & M & Palate & NI & 12 months & Excision & Yes & No \\
\hline Mannarà et al. [20] & Italy & 22 & $\mathrm{~F}$ & Jugal mucosa & 2.0 & 5 years & Excision & No & No \\
\hline Heifetz et al. [11] & USA & 6 & $\mathrm{~F}$ & Jugal mucosa & 4.0 & $\mathrm{NI}$ & Excision & No & No \\
\hline Present study & Brazil & 3 & $\mathrm{~F}$ & Palate & 1.6 & 6 months & Excision & No & No \\
\hline
\end{tabular}

NI: not informed; F: female; M: male. 

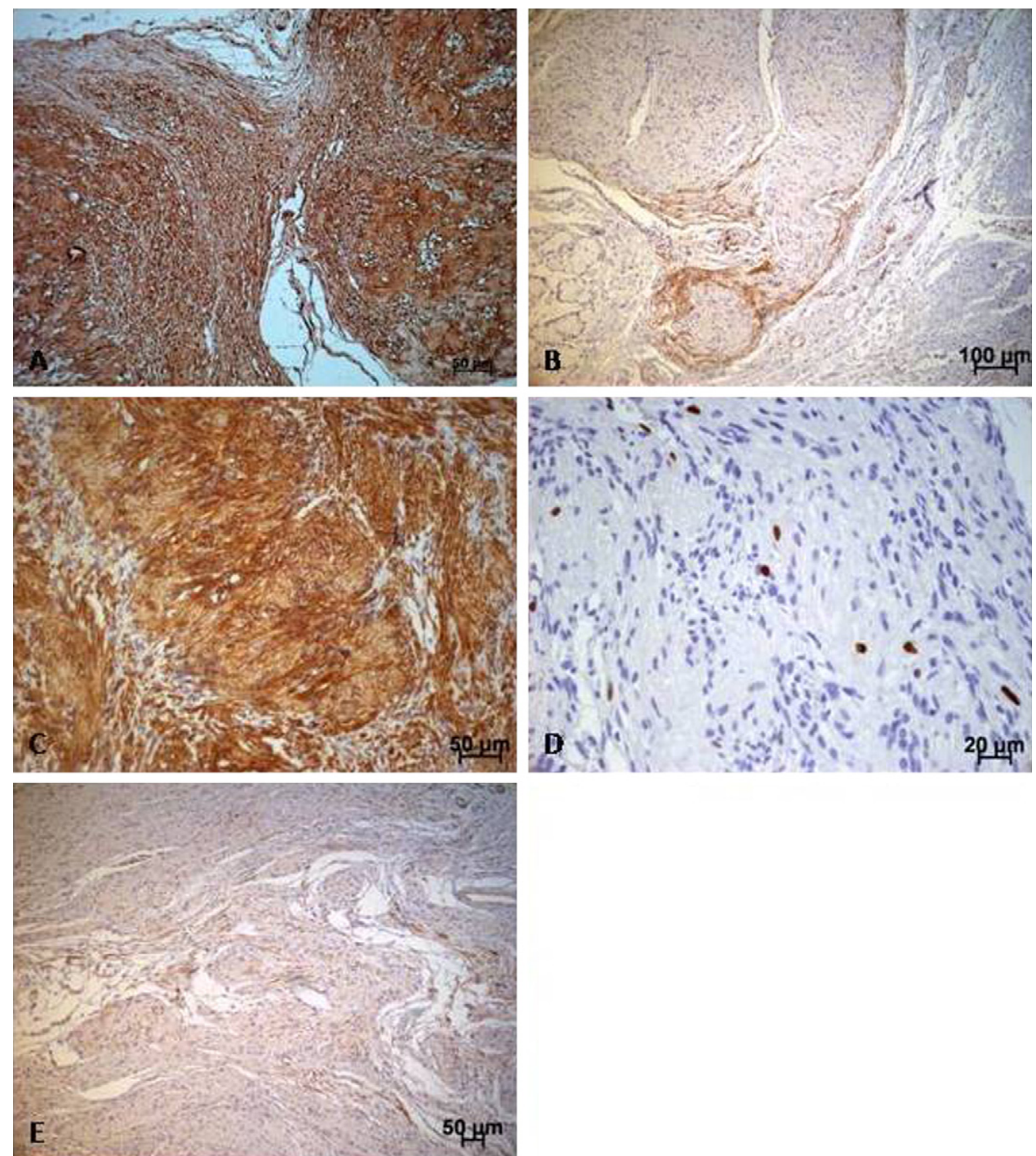

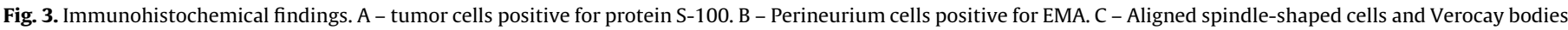
showing immunolabeling for CD56. D - Ki-67 - positive cells were rarely found. E - GFAP-positive spindle-shaped cells were focally observed.

knowledge, this is the first case of plexiform schwannoma observed in a 3-year-old child.

We assessed the English language literature for identifying oral lesions with a plexiform pattern disclosed by a classic schwannoma that received final diagnosis of plexiform schwannoma, resulting in six cases (Table 1 ). The mean age of the patients was 14.4 years (range: 6-22 years). Females were slightly more affected than males. Three cases were located in the buccal mucosa, followed by two cases in the palate. The size of the tumors ranged from 0.7 to $4 \mathrm{~cm}$, with a mean of $1.94 \mathrm{~cm}$. We were not capable of performing molecular testing for detecting neurofibromatosis. However, this association has been reported for plexiform schwannomas involving other sites [10].

Histologically, the present case fulfills the morphological criteria for the diagnosis of plexiform schwannoma $[3,5,7,8,11,12]$. The tumor presented multiple lobules consisting of Schwann cells arranged in areas showing nuclear palisading and containing markedly prominent Verocay bodies, as well as in regions with Antoni B cells, findings similar to those observed in conventional schwannomas [1,2]. Nevertheless, it is impor- tant to establish the differential diagnosis with other peripheral nerve tumors such as plexiform neurofibroma, palisaded encapsulated neuroma and malignant peripheral nerve tumors.

Plexiform neurofibroma is one of the most common tumors of neural origin that grow in a plexiform pattern and is frequently associated with neurofibromatosis type I $[4,13]$. Microscopically, this tumor is characterized by well-defined hypocellular nodules distributed in a myxoid stroma [4]. Although the differentiation of plexiform neurofibroma from plexiform schwannoma is not difficult in view of the classical histological pattern of the former (absence of mitotic figures and intranodular axons), some cases of neurofibroma may exhibit nuclear palisading, a fact that leads to the possible diagnosis of schwannoma $[4,14]$. In this case, the distinction between the two tumors is fundamental because of the tendency of malignant alteration described for plexiform neurofibroma $[4,6,13]$. Furthermore, plexiform neurofibroma may coexist with schwannoma even in the absence of neurofibromatosis [6,7]. No association with this syndrome was observed in the present case, although there are reports of plexiform schwannoma 
associated with neurofibromatosis type II [9], including multiple plexiform schwannomas [6]. Although palisaded encapsulated neuroma is unilobular [15], and may occasionally exhibit a multilobular configuration, little or no nuclear palisading is observed [2]. In addition, many of these multilobular cases present myxoid alterations [15], a feature not observed in plexiform schwannoma. The possibility of a malignant peripheral nerve tumor was ruled out because of the absence of nuclear atypia, pleomorphism and atypical mitoses.

Schwannomas, including the plexiform variant, located in different parts of the human body have shown immunoreactivity to protein S-100 [3,7,16-18], and vimentin [9]. Strong immunoreactivity to these two markers was observed in the present case. In addition, variable immunoreactivity to EMA and GFAP was detected in regions corresponding to the perineurium, in agreement with previous studies $[7,9,16]$. Although rare, positivity for other markers such as CD56 and CD57 has also been observed in benign and malignant schwannomas [16]. In view of the location of the tumor, immunohistochemical staining for AE1/AE3 and calponin was carried out to rule out the possibility of a salivary gland tumor, and staining for these markers was negative. In addition, even in the absence of morphological aspects characterizing a malignant tumor, Ki-67-positive cells were rarely observed [3].

The treatment of choice for plexiform schwannomas is surgical excision $[5,8]$. In the present case, the patient showed no signs of recurrence or any other lesion in other parts of the body one year after surgery.

In conclusion, plexiform schwannoma is a rare lesion in the oral cavity. After reviewing English literature, this is the first reported case of plexiform schwannoma diagnosed in a 3-years-old child. Peripheral nerve sheath and salivary gland tumors located on the mouth should be included in the differential diagnosis of nodular lesions occurring in children.

\section{Conflict of interest}

None declared.

\section{References}

[1] J. Harkin, J. Arrington, R. Reed, Benign plexiform schwannoma: a lesion distinct from plexiform neurofibroma, J. Neuropathol. Exp. Neurol. 37 (1978) 622

[2] C.D. Fletcher, S.E. Davies, Benign plexiform (multinodular) schwannoma: a rare tumour unassociated with neurofibromatosis, Histopathology 10 (1986) 971-980.

[3] K. Terasaki, Y. Mera, H. Uchimiya, Plexiform schwannoma, Clin. Exp. Dermatol. 28 (2003) 372-374.

[4] N.P. Agaram, S. Prakash, C.R. Antonescu, Deep-seated plexiform schwannoma: a pathologic study of 16 cases and comparative analysis with the superficial variety, Am. J. Surg. Pathol. 29 (2005) 1042-1048.

[5] I. Lobo, T. Torres, F. Pina, M. Dominguez, R. Alves, M. Selores, Plexiform schwannoma of the lip mucosa, J. Eur. Acad. Dermatol. Venereol. 23 (2009) 616-618.

[6] H.S. Lim, J. Jung, K.Y. Chung, Neurofibromatosis type 2 with multiple plexiform schwannomas, Int. J. Dermatol. 43 (2004) 336-340.

[7] J.C. Berg, B.W. Scheithauer, R.J. Spinner, C.M. Allen, I.G. Koutlas, Plexiform schwannoma: a clinicopathologic overview with emphasis on the head and neck region, Hum. Pathol. 39 (2008) 633-640.

[8] A. Giovanni, P. Parente, R. Colli, Recurrent plexiform schwannoma in vestibular mucosa, G. Chir. 27 (2006) 105-108.

[9] M. Miettinen, K.M. Shekitka, L.H. Sobin, Schwannomas in the colon and rectum: a clinicopathologic and immunohistochemical study of 20 cases, Am. J. Surg. Pathol. 25 (2001) 846-855.

[10] S. Sheikh, M. Gomes, E. Montgomery, Multiple plexiform schwannomas in a patient with neurofibromatosis, J. Thorac. Cardiovasc. Surg. 115 (1998) 240-242.

[11] S.A. Heifetz, A.M. Sadove, M.L. Joyner, D. Davidson, Intraoral plexiform (multinodular) neurilemoma, Pediatr. Pathol. 11 (1991) 457-465

[12] L.S. Marocchio, D.T. Oliveira, M.C. Pereira, C.T. Soares, R.N. Fleury, Sporadic and multiple neurofibromas in the head and neck region: a retrospective study of 33 years, Clin. Oral Investig. 11 (2007) 165-169.

[13] R. Rahbar, B.G. Litrovnik, S.O. Vargas, C.D. Robson, R.C. Nuss, M.B. Irons, et al., The biology and management of laryngeal neurofibroma, Arch. Otolaryngol. Head Neck Surg. 130 (2004) 1400-1406.

[14] J.M. Woodruff, M.L. Marshall, T.A. Godwin, J.W. Funkhouser, N.J. Thompson, R.A. Erlandoson, et al., Plexiform (multinodular) schwannoma: a tumor simulating the plexiform neurofibroma, Am. J. Surg. Pathol. 7 (1983) 691-697.

[15] N. Misago, T. Inoue, Y. Narisawa, Unusual benign myxoid nerve sheath lesion: myxoid palisaded encapsulated neuroma (PEN) or nerve sheath myxoma with PEN/PEN-like features? Am. J. Dermatopathol. 29 (2007) 160-164.

[16] A.F. Nascimento, C.D. Fletcher, The controversial nosology of benign nerve sheath tumors: neurofilament protein staining demonstrates intratumoral axons in many sporadic schwannomas, Am. J. Surg. Pathol. 31 (2007) 1363-1370.

[17] S.C. Talwalkar, L. Cutler, J.H. Stilwell, Multiple plexiform schwannoma of the hand and forearm: a long-term follow-up, J. Hand Surg. 30 (2005) 358-360.

[18] W.Y. Chuang, C.J. Yeh, S.T. Huang, S.M. Jung, Plexiform schwannoma of the clitoris, APMIS 115 (2007) 889-890.

[19] S.O. Krolls, J.P. McGinnis Jr., D. Quon, Multinodular versus plexiform neurilemoma of the hard palate. Report of a case, Oral Surg. Oral Med. Oral Pathol. 77 (1994)154-157.

[20] G.M. Mannarà, F.C. La Rosa, F. Marino, Plexiform schwannoma of the cheek, J. Laryngol. Otol. 113 (1999) 1034-1035. 